Абдулгалимов Р.3., Сунцов А.П.

\title{
ДЕЯТЕЛЬНОСТЬ ОБЩЕСТВЕННЫХ ОБЪЕДИНЕНИЙ КАК ОСНОВНАЯ ФОРМА УЧАСТИЯ ГРАЖДАН В УПРАВЛЕНИИ ДЕЛАМИ ГОСУДАРСТВА
}

Аннотация: Предметом исследования данной статьи являются закономерности участия общественньх объединений в управлении делами государства. Раскрываются условия и другие обстоятельства сотрудничества органов государственной власти и общественных объединений, рассматриваются особенности правового статуса общественных объединений, непосредственно участвуюших в управлении делами государства. В этой связи в статье дается понятие и содержание правового статуса общественных объединений как основной формы участия населения в управлении делами государственной политики. В статье также анализируется специфика правового статуса общественных объединений. С позищий материалистической диалектики авторами широко используются методы диалектического познания, а также общуенаучные методы познания - исторический, системный, обобщение и анализ научных, нормативных и практических материалов Научная новизна заключается в исследовании правового статуса общественных объединений в управлении делами государства в рамках современного законодательства, в том числе вопросов правового положения названных объединений, особенностей их создания и деятельности, их участия в политических процессах, происходящчи в Российской Федерации. В частности, в работе на основе переосмысление такого явления, как общественное объединение, его роли в современном реформировании России, автор приходит к выводу, что общественные объединения вносят существенный вклад в процесс развития гражданского общества, давая гражданам возможность прямого участия в управлении делами государства, в выражении своей воли в проиессе взаимодействия с государством.

Review: The object of studies in this article involves the patterns of participation of non-governmental organizations in managing public affairs of the state. The authors discuss conditions and other circumstances regarding cooperation between the state government bodies and non-governmental organizations, evaluating specific features of the legal status of the NGOs participating in managing affairs of the state. In this respect the article provides definition and elements of the legal status of the non-governmental organizations as the main form of participation of people in implementation of the state government policy. The article also includes analysis of the specific features of the legal status of the NGOs. From the standpoint of materialistic dialectics the authors employ the methods of dialectic cognition, as well as the general scientific cognition methods - historical, systemic, generalization and analysis of scientific, normative and practical materials. The scientific novelty is due to the studies of the legal status of non-governmental organization within the framework of managing public affairs according to the current legislation, including the issues regarding their legal position, specific features of their formation and participation in the ongoing political processes in the Russian Federation. In particular, the authors reevaluate the non-governmental organization and its role in the modern Russian reform, drawing a conclusion that the non-governmental organizations have a significant impact into the process of development of the civil society, allowing the citizens to directly participate in managing affairs of the state, expressing their opinions in the process of interaction with the state. Ключевые слова: Общественные объединения, граждане, дела государства, конституционное право, демократия, государство, правовой статус, обиество, управление, население.

Keywords: Non-governmental organizations, citizens, affairs of the state, constitutional law, democracy, state, legal status, society, administration, population. 
A ктуальность вовлечения граждан в управление делами государства побуждает нас к уяснению правового регулирования деятельности общественных объединений, в том числе в реализации этого конституционного права (ч.1 ст. 32). Реализация конституционно гарантированной возможности участия граждан в управлении государственными делами имеет большой потенциал и «...заключается: как в фундаментальном праве народа выбирать власть, так и в возможности непрерывно влиять на власть и процесс принятия ею решений». ${ }^{1}$

В России сложились действенные механизмы постоянного и прямого взаимодействия институтов публичной власти и политических партий, диалог с профсоюзами и национально-культурными объединениями, каналы общественного контроля, «обратной связи» с другими общественными объединениями.

Основой правового регулирования деятельности общественных объединений в отечественном законодательстве являются нормы Конституции Российской Федерации, в частности нормы второй главы «Права и свободы человека и гражданина». Во-первых, регулированию общественных объединений посвящены нормы статьи 13 Конституции Российской Федерации, 4 пункт которой гласит, что общественные объединения равны перед законом ${ }^{2}$. Во-вторых в пункте 5 этой же статьи Конституция Российской Федерации накладывает некоторые ограничения на создание объединений, в соответствии с которыми запрещается создание и деятельность общественных объединений, цели или действия которых направлены на насильственное изменение основ конституционного строя и нарушение целостности Российской Федерации, подрыв безопасности государства, создание вооруженных формирований, разжигание социальной, расовой, национальной и религиозной розни. ${ }^{3}$

\footnotetext{
${ }^{1}$ Путин В.В. Демократия и качество государства // Газета «Коммерсантъ», №20/П (4805), от 6 февраля 2012 года.

2 Конституция Российской Федерации: принята всенародным голосованием 12 декабря 1993 года (по состоянию на 30.12.2008 г.) // Российская газета.- 2009.-21 января

${ }^{3}$ Конституция Российской Федерации: принята всенародным голосованием 12 декабря 1993 года (по состоянию на 30.12.2008 г.) // Российская газета.- 2009.-21 января
}

Данные положения находят свое развитие и в статье 30 , в которой говорится, что «каждый имеет право на объединение, включая право создавать профессиональные союзы для зашиты своих интересов. Свобода деятельности общественных объединений гарантируется. Никто не может быть принужден к вступлению в какое-либо объединение или пребыванию в нем». ${ }^{4}$

Право каждого на объединение, свобода деятельности общественных объединений, являются одним из важнейших конституционных прав человека, поскольку «составной частью демократического правового государства, каковым провозглашена Российская Федерация, его гражданского общества являются общественные объединения различных слоев населения, которые выступают в качестве связующего звена между государством и обществом в процессе проведения в стране крупномасштабных политических и социально-культурных преобразований и одним из наиболее активных участников этих мероприятий». ${ }^{5}$

Особенности правового статуса общественных объединений, участвующих в управлении делами государства, логичнее будет рассмотреть при помощи анализа специфики его отдельных составляющих.

Гарантии прав определяют в науке различными способами. В юридической литературе выделяется достаточно много видов гарантий. Некоторыми авторами выделяются экономические, социальные, политические, идеологические, юридические, организационные гарантии. ${ }^{6}$

Применительно к общественным объединениям видится целесообразным рассмотреть лишь юридические (правовые) гарантии прав и обязанностей организаций, участвующих в управлении делами государства. Л.М. Архангельский считает, что «правовые гарантии личности, гражданина являются необходимой составной частью правового ста-

\footnotetext{
${ }^{4}$ Конституция Российской Федерации: принята всенародным голосованием 12 декабря 1993 года (по состоянию на 30.12.2008 г.) // Российская газета.- 2009.-21 января

${ }^{5}$ Кожевников О. А. Конституционно-правовой статус общественных объединений и его реализация в Российской Федерации. дис. ... канд. юрид. наук. Москва. 2003. С. 38.

${ }^{6}$ Конституция развитого социализма: исторические предпосылки и значение. Институт истории СССР (Академия наук СССР). - М.: Наука. 1981. С. 149.
} 


\section{Политика и общество 7 (115) • 2014}

туса и эффективным его компонентом». ${ }^{7}$ Т.Е. Абова, А.И. Лукьянов, Г.Х, Шахназаров, Б.Н. Тонорнин определяют юридические гарантии граждан как «совокупность правовых норм, обеспечивающих осуществление конституционных прав граждан и возможность правовой защиты». ${ }^{8}$

Таким образом, правовые гарантии общественных объединений, участвующих в управлении делами государства - это такие нормы права, которые обеспечивают реализацию их компетенции.

На основе анализа нормативно-правовых актов, регулирующих вопросы создания и деятельности отдельных государственно-общественных объединений, следует сделать вывод о том, что нормативно-правовыми актами предусмотрены определенные гарантии как компетенции общественных объединений, участвующих в управлении делами государства в целом, так и их членов. ${ }^{9}$

К правовым гарантиям их деятельности относятся:

1. Гарантии государством правовой основы их деятельности. Это означает, что государство принимает соответствующие нормативно-правовые акты, регулирующие деятельность общественных объединений, участвующих в управлении делами государства.

2. Государство обеспечивает регистрацию общественных объединений, участвующих в управлении делами государства (в случае, если такая регистрация является обязательной), что представляется особенно важным, в силу того, что юридическая природа последних еще концептуально не разработана, а, следовательно, нормативно не закреплена.

Среди гарантий деятельности членов общественных объединений, участвующих в управлении делами государства различаются:

1. Освобождение члена общественного объединения, участвующего в управлении делами государства от выполнения обязанностей

7 Л.М. Архангельский. Социализм и личность. - М.: Мысль, 1979. C. 227.

${ }^{8}$ Т.Е. Абова, А.И. Лукьянов, Г.Х, Шахназаров, Б.Н. Тонорнин. Конституция страны советов: словарь. - М.: Издательство политической литературы. 1982. С. 51.

9 Пиманова М.А. Правовой статус государственно-общественных объединений (конституционно-правовое исследование). дис. ... канд. юрид. наук. Тюмень. 2007. С. 87. по основному месту работы с сохранением за ним должности. ${ }^{10}$

2. Возмещение расходов связанных с осуществлением полномочий члена таких объединений. ${ }^{11}$

3. Запрет отзыва члена общественного объединения, участвующего в управлении делами государства. ${ }^{12}$

Все общественные объединения, участвующие в управлении делами государства следуют ряду общих организационных принципов.

Под принципами правового статуса общественных объединений, участвующих в управлении делами государства мы понимаем такие основополагающие руководящие положения, которые определяют их правовой статус.

Важнейший из этих принципов - легальность формы их существования. Это значит, что они, обязаны в своей деятельности руководствоваться и соблюдать закон и правопорядок, а значит соблюдать нормы права, которые содержатся в Конституции, законах и основанных на них подзаконных актах.

Также важнейшим принципом общественных объединений, участвующих в управлении делами государства является презумпция независимости. Этот принцип предполагает, что к ним следует относить только такие организации, которые способны действовать независимо от всех субъектов общественных отношений, которые могут оказывать влияние на их работу. Принцип независимости общественных объединений, участвующих в управлении делами государства достаточно прочно защищается Федеральным законом «Об общественных объединениях». Ст. 17 Закона, которая регулирует взаимоотношения государства с общественными объединениями гласит: «Вмешательство органов государственной власти и их должностных лиц в деятельность общественных

${ }^{10}$ Например, п. 1, Ст. 13 Федерального закона от 04.04.2005 № 32-Ф3 «Об общественной палате Российской Федерации» // СЗ РФ. 2005. № 15. Ст. 1277.

${ }^{11}$ Например, п. 2, Ст. 13 Федерального закона от 04.04.2005 № 32-Ф3 «Об общественной палате Российской Федерации» // С3 РФ. 2005. № 15. Ст. 1277.

${ }^{12}$ Например, п. 3, Ст. 13 Федерального закона от 04.04.2005 № 32-Ф3 «Об общественной палате Российской Федерации» // C3 РФ. 2005. № 15. Ст. 1277 
объединений... не допускается, за исключением случаев, предусмотренных настоящим Федеральным законом» ${ }^{13}$.

Необходимо подчеркнуть, тот факт, что им предоставляется определенная свобода действий. В данном случае речь идет о поиске наиболее эффективных форм социального партнерства, при котором как государственные так общественные структуры не должны находиться на «разных сторонах баррикады», а взаимодействовать в решении единых конституционных задач.

Политическая независимость также является важным компонентом презумпции независимости общественные объединения, участвующие в управлении делами государства. Вместе с тем нередко встречается мнение, что они не могут обладать полной политической независимостью.

Юридическая и оперативная самостоятельность означает возможность общественных объединений, участвующих в управлении делами государства вести свою повседневную деятельность независимо от какого-либо другого лица, организации, ведомства или органа. В этом отношении трудно переоценить наличие прочной законодательной базы, которая четко определяла бы сферу самостоятельности таких общественных объединений. Как правило, они пользуются правом устанавливать свои правила, процедуры, и эти правила не подлежат изменениям извне.

Независимой должна быть и процедура назначения и увольнения персонала, который работает в политико-публичном общественном объединений. Условия, применяемые в отношении персонала политико-публичных общественных объединений, должны конкретно излагаться в учредительных актах, этих объединений

Немаловажное значение имеет и состав общественных объединений, участвующих в управлении делами государства, который также является своего рода гарантией от вмешательства государственных органов. В статье 19 Федерального закона «Об общественных объединениях» говорится о том, что, «Органы государственной власти и органы местного самоуправления не могут быть учредителями, членами и участниками общественных объединений» ${ }^{14}$.

\footnotetext{
13 Федеральный закон от 19.05.1995 № 83-Ф3 «Об общественных объединениях» // СЗ РФ. 1995. № 21. Ст. 1930.

14 Федеральный закон от 19.05.1995 № 83-Ф3 «Об общественных объединениях» // СЗ РФ. 1995. № 21. Ст. 1930.
}

Принцип взаимодополняемости возможностей общества и государства в достижении общих целей также является немаловажным. Обособление данного принципа тем более важно, что в литературе делаются попытки выделить в таких объединениях государственные и общественные составляющие, их ядром, сущностью называлось соединение частных и публичных начал. Ямпольская Ц.А. называет это «профессионализмом и специализацией» говоря о том, что у компетентных представителей общественности имеются некоторые преимущества перед штатными работниками госаппарата. ${ }^{15}$

Добровольность участия. Данный принцип представляется также немаловажным при определении правового статуса рассматриваемых объединений. Он означает, что никто не может быть заставлен состоять и принимать участие в деятельности рассматриваемых объединений.

Равенство прав участников. Данный принцип означает наделение представителей, как гражданского общества, так и государства равными полномочиями при решении подведомственных вопросов. Участие государства и гражданского общества в рамках рассматриваемых объединений равнозначно, усилия сторон направлены на решение вопросов, представляющих общий интерес. ${ }^{16}$

Учет мнения общественных объединений, участвующие в управлении делами государства. Данный принцип связан с дальнейшей судьбой решений общественных объединений. В данном случае речь идет не об обязательности исполнения таких решений, а только об учете, принятии к сведению, оценке таких решений государственными органами. ${ }^{17}$ Как отмечает С.А. Авакьян, обязательность решений свойственна формам прямой демократии, таким как референдум и прямые выборы, а при консультативных формах прямой демократии этот признак обязательности решений не является непременным. ${ }^{18}$

${ }^{15}$ Ц.А. Ямпольская. Общественные организации в СССР. М.: Наука. 1972. С. 127-128.

16 Пиманова М.А. Правовой статус государственно-общественных объединений (конституционно-правовое исследование). дис. ... канд. юрид. наук. Тюмень. 2007. С. 90.

17 Пиманова М.А. Правовой статус государственно-общественных объединений (конституционно-правовое исследование). дис. ... канд. юрид. наук. Тюмень. 2007. С. 91.

${ }_{18}$ С.А. Авакьян. Проблемы народного представительства в российской Федерации. - М.: Издательство Московского государственного университета. 1998. С. 93. 


\section{Политика и общество 7 (115) • 2014}

Исходя из всего вышесказанного, проведя анализ российских и зарубежных источников по теме исследования, можно прийти к выводу, что общественные объединения, участвующие в управлении делами государства - это один из способов непосредственного участия граждан в управлении делами государства, что является одним из важнейших институтов демократии.

Согласившись с большинством ученых, можно сделать вывод о том, что правовой статус - это положение определенных субъектов, закрепленное нормами права и разнящееся только системой прав и обязанностей. Также большинство авторов, понимают «правовой статус»в широком смысле, и включают в него, помимо прав и обязанностей, дополнительные элементы такие как, гарантии прав и обязанностей, принципы правового статуса и юридическую ответственность.

Таким образом, общественные объединения являются основной формой непосредственного участия граждан в управлении делами государства и вносят свой вклад в процесс развития гражданского общества, давая гражданам возможность прямого участия в выражении своей воли в процессе взаимодействия с государством.

\section{Библиография:}

1. Конституция Российской Федерации: принята всенародным голосованием 12 декабря 1993 года (по состоянию на 05.02.2014) // С3 РФ, 2014, № 9, ст.851.

2. Федеральный закон от 19.05.1995 № 83-Ф3 «Об общественных объединениях» // С3 РФ. 1995. № 21. Ст. 1930.

3. Федеральный закон от 04.04.2005 № 32-Ф3 «Об общественной палате Российской Федерации» // С3 РФ. 2005. № 15. СТ. 1277.

4. Путин В.В. Демократия и качество государства // Газета «Коммерсантъ», №20/П (4805), от 6 февраля 2012 года

5. Конституция развитого социализма: исторические предпосылки и значение. Институт истории СССР (Академия наук СССР). - М.: Наука. 1981. С. 149.

6. Кожевников О. А. Право некоммерческих организаций в Российской Федерации (Конститу- ционно-правовое исследование) автореф. дис. на соиск. учен. степ. докт. юрид. наук. Екатеринбург. 2008. С. 51

7. Архангельский Л.М. Социализм и личность. М.: Мысль, 1979. С. 227..

8. Абова Т.Е., Лукьянов А.И., Шахназаров Г.Х., Тонорнин Б.Н. Конституция страны советов: словарь. - М.: Издательство политической литературы. 1982. С. 51.

9. Пиманова М.А. Правовой статус государственно-общественных объединений (конституционно-правовое исследование). дис. ... канд. юрид. наук. Тюмень. 2007. С. 87.

10. Ц.А. Ямпольская. Общественные организации в СССР. - М.: Наука. 1972. С. 127-128.

11. С.А. Авакьян. Проблемы народного представительства в российской Федерации. - М.: Издательство Московского государственного университета. 1998. С. 93.

12. Сунцов А.П., Тихий Р.С. Роль административной процедуры лицензирования в обеспечении прав и свобод граждан на получение социальных льгот. // Вестник Тюменского государственного университета. 2006. № 1. С. 145-150.

13. Борисенков А.А. Современная российская конституция о власти // NB: Вопросы права и политики. - 2014. - 1. - C. 19-44. DOI: 10.7256/23059699.2014.1.10585. URL: http://www.e-notabene. $\mathrm{ru} / \mathrm{lr} /$ article_10585.html

14. Грудцына Л.Ю., Петров С.М. Власть и гражданское общество в России: взаимодействие и противо-стояние // Административное и муниципальное право. - 2012. - 1. - С. 19-29.

15. Сунцов А.П., Гиберт А.Н. К вопросу об особенностях правового института избирательных комиссий автономных округов. // Вестник Тюменского государственного университета. 2011. № 3. С. 81-86.

16. Щупленков О.В., Щупленков Н.О. Проблемы взаимодействия гражданского общества и государства в современной России // NB: Вопросы права и политики. - 2013. - 4. - C. 1-55. DOI: 10.7256/23059699.2013.4.585. URL: http://www.enotabene.ru/lr/article_585.html

17. Мишунина А.А., Сунцов А.П. Актуальные вопросы совершенствования деятельности представительных органов власти по оказанию бесплатной юридической помощи гражданам. // 
Вестник Тюменского государственного университета. 2013. № 3. С. 105-113.

18. Зайцев А.В. Принцип обратной связи и институционализация диалога государства и гражданского общества // NB: Проблемы общества и политики. - 2012. - 2. - C. 1-21. URL: http:// www.e-notabene.ru/pr/article_125.html

19. Зайцев А.В. Институциональный диалог в сфере коммуникации государства и гражданского общества: теоретико-методологический подход // NB: Проблемы общества и политики. - 2012. - 1. - C. 21-54. URL: http://www.e-notabene.ru/ pr/article_110.html

20. Зайцев А.В. Институционализация публичных дебатов во Франции и диалог государства и гражданского общества в публичной политике современной России: сравнительный анализ // NB: Проблемы общества и политики. - 2014. - 5. - С. 1-41. DOI: 10.7256/23060158.2014.5.12120. URL: http://www.e-notabene. ru/pr/article_12120.html

21. Сунцов А.П. Актуальные вопросы совершенствования деятельности избирательных комиссий по повышению правовой культуры избирателей. //Академический юридический журнал. 2012. № 48. С. 13-16.

22. Знаменский Д.Ю. Государство и гражданское общество в процессе формирования приоритетов государственной научно-технической политики // NB: Проблемы общества и политики. - 2013. - 10. - C. 1-17. DOI: 10.7256/2306-0158.2013.10.9489. URL: http:// www.e-notabene.ru/pr/article_9489.html

23. Кодан С.В., Владимирова Г.Е. Правовое оформление в Основных государственных законах Российской империи 1832-1892 гг. изд. организации верховной государственной власти // NB: Исторические исследования. - 2013. - 3. C. 44-78. DOI: 10.7256/2306-420X.2013.3.748. URL: http://www.e-notabene.ru/hr/article_748. html

24. Сунцов А.П., Мишунина А.А. Транзитный проезд иностранных граждан через территорию Российской Федерации : проблемы и перспективы. // Правовая политика и правовая жизнь. 2008. № 1. С. 102-108.

25. И. Д. Короева Философия взаимодействия власти и народа // Политика и Общество. - 2012. 4. - С. $18-24$.

\section{References (transliteration):}

1. Putin V.V. Demokratiya i kachestvo gosudarstva // Gazeta "Kommersant" ", №20/P (4805), ot 6 fevralya 2012 goda

2. Kozhevnikov O. A. Pravo nekommercheskikh organizatsii v Rossiiskoi Federatsii (Konstitutsionno-pravovoe issledovanie) avtoref. dis. na soisk. uchen. step. dokt. yurid. nauk. Ekaterinburg. 2008. S. 51

3. Arkhangel'skii L.M. Sotsializm i lichnost'. - M.: Mysl', 1979. S. 227. .

4. Abova T.E., Luk'yanov A.I., Shakhnazarov G.Kh., Tonornin B.N. Konstitutsiya strany sovetov: slovar'. - M.: Izdatel'stvo politicheskoi literatury. 1982. S. 51.

5. Pimanova M.A. Pravovoi status gosudarstvennoobshchestvennykh ob' edinenii (konstitutsionnopravovoe issledovanie). dis. ... kand. yurid. nauk. Tyumen'. 2007. S. 87.

6. Ts.A. Yampol'skaya. Obshchestvennye organizatsii v SSSR. - M.: Nauka. 1972. S. 127-128.

7. S.A. Avak'yan. Problemy narodnogo predstavitel'stva $\mathrm{v}$ rossiiskoi Federatsii. - M.: Izdatel'stvo Moskovskogo gosudarstvennogo universiteta. 1998. S. 93.

8. Suntsov A.P., Tikhii R.S. Rol' administrativnoi protsedury litsenzirovaniya $\mathrm{v}$ obespechenii prav $\mathrm{i}$ svobod grazhdan na poluchenie sotsial'nykh l'got. // Vestnik Tyumenskogo gosudarstvennogo universiteta. 2006. № 1. S. 145-150.

9. Borisenkov A.A. Sovremennaya rossiiskaya konstitutsiya o vlasti // NB: Voprosy prava i politiki. - 2014. - 1. - C. 19-44. DOI: 10.7256/23059699.2014.1.10585. URL: http://www.e-notabene. ru/lr/article_10585.html

10. Grudtsyna L.Yu., Petrov S.M. Vlast' i grazhdanskoe obshchestvo v Rossii: vzaimodeistvie i protivo-stoyanie // Administrativnoe i munitsipal'noe pravo. - 2012. - 1. - C. 19-29.

11. Suntsov A.P., Gibert A.N. K voprosu ob osobennostyakh pravovogo instituta izbiratel'nykh komissii avtonomnykh okrugov. // Vestnik Tyumenskogo gosudarstvennogo universiteta. 2011. № 3. S. 81-86.

12. Shchuplenkov O.V., Shchuplenkov N.O. Problemy vzaimodeistviya grazhdanskogo obshchestva i gosudarstva v sovremennoi Rossii // NB: Voprosy prava i politiki. - 2013. - 4. - C. 1-55. 


\section{Политика и общество 7 (115) • 2014}

DOI: 10.7256/2305-9699.2013.4.585. URL: http:// www.e-notabene.ru/lr/article 585.html

13. Mishunina A.A., Suntsov A.P. Aktual'nye voprosy sovershenstvovaniya deyatel'nosti predstavitel'nykh organov vlasti po okazaniyu besplatnoi yuridicheskoi pomoshchi grazhdanam. // Vestnik Tyumenskogo gosudarstvennogo universiteta. 2013. № 3. S. 105-113.

14. Zaitsev A.V. Printsip obratnoi svyazi i institutsionalizatsiya dialoga gosudarstva i grazhdanskogo obshchestva // NB: Problemy obshchestva i politiki. 2012. - 2. - C. 1-21. URL: http://www.e-notabene. $\mathrm{ru} / \mathrm{pr} / \mathrm{article} 125 . \mathrm{html}$

15. Zaitsev A.V. Institutsional'nyi dialog $\mathrm{V}$ sfere kommunikatsii gosudarstva i grazhdanskogo obshchestva: teoretiko-metodologicheskii podkhod // NB: Problemy obshchestva i politiki. -2012 . -1 . - C. 21-54. URL: http://www.e-notabene.ru/pr/article_110.html

16. Zaitsev A.V. Institutsionalizatsiya publichnykh debatov vo Frantsii i dialog gosudarstva i grazhdanskogo obshchestva v publichnoi politike sovremennoi Rossii: sravnitel'nyi analiz // NB: Problemy obshchestva i politiki. - 2014. - 5. - C. 1-41. DOI: 10.7256/2306-0158.2014.5.12120. URL: http://www.e-notabene.ru/pr/article_12120.html
17. Suntsov A.P. Aktual'nye voprosy sovershenstvovaniya deyatel'nosti izbiratel'nykh komissii po povysheniyu pravovoi kul'tury izbiratelei. //Akademicheskii yuridicheskii zhurnal. 2012. № 48. S. 13-16.

18. Znamenskii D.Yu. Gosudarstvo i grazhdanskoe obshchestvo v protsesse formirovaniya prioritetov gosudarstvennoi nauchno-tekhnicheskoi politiki // NB: Problemy obshchestva i politiki. -2013. - 10.C. 1-17. DOI: 10.7256/2306-0158.2013.10.9489. URL: http://www.e-notabene.ru/pr/article_9489.html

19. Kodan S.V., Vladimirova G.E. Pravovoe oformlenie v Osnovnykh gosudarstvennykh zakonakh Rossiiskoi imperii 1832-1892 gg. izd. organizatsii verkhovnoi gosudarstvennoi vlasti // NB: Istoricheskie issledovaniya. - 2013. - 3. - C. 4478. DOI: 10.7256/2306-420X.2013.3.748. URL: http://www.e-notabene.ru/hr/article_748.html

20. Suntsov A.P., Mishunina A.A. Tranzitnyi proezd inostrannykh grazhdan cherez territoriyu Rossiiskoi Federatsii : problemy i perspektivy. // Pravovaya politika i pravovaya zhizn’. 2008. № 1 . S. 102-108.

21. I. D. Koroeva Filosofiya vzaimodeistviya vlasti i naroda // Politika i Obshchestvo. - 2012. - 4. - C. $18-24$. 